\title{
Glutamine and Liver Dysfunction Elicited by Intestinal Ischemia- Reperfusion Injury
}

\author{
I. Goulimaris*,1, D. Kanellos ${ }^{1}$, D. Kazantzidou ${ }^{1}$, E. Kaldrimidou ${ }^{2}$, G. Papageorgiou ${ }^{3}$, E. Tsali ${ }^{2}$, \\ I. Kanellos ${ }^{1}$ and D. Betsis ${ }^{1}$ \\ ${ }^{1} 4^{\text {th }}$ Surgical Department - Medical School, ${ }^{2}$ Pathology Department - Veterinary School, ${ }^{3}$ Laboratory of Biological \\ Chemistry - Medical School, Aristotle University of Thessaloniki, Greece
}

\begin{abstract}
Intestinal ischemia-reperfusion (IIR) injury affects other organs, like the liver. Glutamine may offer liver protection, following IIR injury. Four groups of rats were studied. In Group A, the animals were subjected to 90 minutes of IIR. In Group B Alanyl-Glutamine dipeptide was administered prior to IIR. Group C, was the sham, and in Group D, the animals were given Alanyl-Glutamine dipeptide, only. Malondialdehyde, myeloperoxidase, and total glutathione were measured in liver tissue, and transaminases in the serum. Liver tissue samples were examined under electron microscopy. Malondialdehyde values in Groups A and B were significantly higher and total glutathione levels were significantly lower, compared to Groups C and D. SGPT values of Group A were significantly higher than Groups C and D. Electron microscopy examination of Group A animals showed endothelial cell degeneration. In Group B, hepatic cell changes were unremarkable. The administration of Alanyl-Glutamine dipeptide, prior to IIR, protected hepatocytes from oxidative injury.
\end{abstract}

\section{INTRODUCTION}

Intestinal ischemia-reperfusion injury has been implicated in both local and systemic reactions. The production of oxygen radicals, during reperfusion, is responsible for the oxidation of the unsaturated fatty acids of the endothelial cells membrane [1]. Endothelial cells also produce adhesion molecules (ICAM-1, P-selectin, E-selectin) that react with the neutrophils which accumulate at the site of injury [2]. Adherent neutrophils are activated and release enzymes like myeloperoxidase and elastase that contribute to the local injury [3]. The consequences of local microvascular injury are destruction of the normal gut barrier function and insertion of bacteria, endotoxin, activated neutrophils, and other inflammatory cells (cytokines) in the systematic circulation, affecting other organs $[4,5]$.

The liver is the first organ affected by intestinal ischemia-reperfusion and its injury has been described as reduction in the portal vein blood flow, accumulation of neutrophils in midzonal (zone 2) sinusoids with reduction of blood flow, hypoxia of liver cells at the pericentral (zone 3) region with reduced ATP, reduced bile flow, and elevated transaminases in serum $[6,7]$.

Glutamine, a non-essential aminoacid, has been used in experimental studies, attenuating the liver injury from toxic agents, probably through the antioxidant system of glutathione (GSH) $[8,9]$. Glutamine may play a protective role to the liver injury, following intestinal ischemia-reperfusion.

The aim of our study is to investigate the effect of glutamine, given prior to intestinal ischemia-reperfusion injury.

*Address correspondence to this author at the Adelfon Emmanouil 34. GR 54454, Thessaloniki, Greece; Tel: 00302310937410; Fax: 00302310260491; E-mail: ygouli@in.gr

\section{MATERIALS AND METHODOLOGY}

The National Research Council's guide for the care and use of laboratory animals was followed, and the study was approved by the Animal Care Committee. Forty male Wistar rats ( 2 months old), weighing $250 \pm 15 \mathrm{~g}$, were allocated into 4 groups of 10 each. The rats were kept under a 12-hour light/dark cycle, and permitted ab libitum access to standard laboratory rodent chow and tap water. The rats were anesthetized with thiopental sodium (Pentothal, Abbott) $40 \mathrm{mg} / \mathrm{kg}$, intraperitoneally.

In Group A the superior mesenteric artery was dissected and occluded for 30 minutes, with an atraumatic vascular clamp, followed by a reperfusion time of 60 minutes. At the end of the reperfusion time a part of the liver was removed for biochemical and histological analysis, and blood from the heart was taken for serum analyses. By this way the animals were sacrificed.

In Group B the rats were given alanyl-glutamine dipeptide ((Dipeptiven, Fresenius, A.G., Germany) $0.4 \mathrm{~g} / \mathrm{kg} / \mathrm{day}$, intraperitoneally, 48 and 24 hours before the same intestinal ischemia-reperfusion experiment, as in Group A.

In Group C (sham) the rats were anesthetized, and the superior mesenteric artery was dissected but it was not occluded, for 90 minutes.

In Group D the rats were given Alanyl-Glutamine dipeptide, like in Group B, without any further intervention.

The biochemical measurements in liver tissue included: myeloperoxidase (MPO), malondialdehyde (MDA), an end product of lipid peroxidation, total glutathione (GSH), and in the serum the transaminases SGOT, SGPT.

\section{Determination of MPO in Liver Tissue}

Tissue samples were homogenized with $0.5 \%$ Hexadecyltrimethyl-ammonium bromide (HTAB) in $50 \mathrm{mM}$ potassium 
phosphate buffer, $\mathrm{pH} 6$ (1:10), and were centrifuged at $2000 \mathrm{rpm}$ for $10 \mathrm{~min}$. The supernatant was mixed with potassium phosphate buffer, which contained $1.67 \mathrm{mg} / \mathrm{mL}$ odianisidine dihydrocloride and $0.05 \% \mathrm{H}_{2} \mathrm{O}_{2}$, and the MPO activity was assessed spectrophotometrically at $460 \mathrm{~nm}$ for 0,30 , and $90 \mathrm{sec}$. One unit of the enzyme activity was defined as the amount of MPO causing an absorbance change of 1.0/min per $\mathrm{g}$ of tissue $(\mathrm{U} / \mathrm{g})$.

\section{Determination of MDA in Liver Tissue}

Tissue samples were homogenized with $50 \mathrm{mM}$ potassium phosphate buffer, $\mathrm{pH} 6.5$ (1:10), and were centrifuged at $2000 \mathrm{rpm}$ for $10 \mathrm{~min}$. The supernatant $(0.5 \mathrm{~mL})$ was mixed with $0.5 \mathrm{~mL}$ aqueous thiobarbituric acid (TBA) solution $0.8 \%$, and $0.5 \mathrm{~mL}$ aqueous trichloroacetic acid (TCA) solution $10 \%$. The mixture was submitted to spectrophotometry in the range of 400-650 nm.

\section{Determination of Total GSH in Liver Tissue}

Glutathione Assay Kit (Cayman Chemical) was used. Tissue samples were homogenized with cold buffer (1:10), $50 \mathrm{mM}$ 2-(N-morpholino)ethanesulphonic acid (MES), $\mathrm{pH}$ 6-7, containing $1 \mathrm{mM}$ ethylenediaminotetraacetic acid (EDTA), per gram tissue, and were centrifuged at $10000 \mathrm{rpm}$ for $15 \mathrm{~min}$, in $4^{\circ} \mathrm{C}$. The supernatant was deproteinated with equal volume of metaphosphoric acid (MPA), and then triethanolamine (TEAM) $(50 \mu \mathrm{L}$ per $\mathrm{mL}$ of supernatant) was added increasing the $\mathrm{pH}$ of the sample. The samples $(50 \mu \mathrm{L})$ were prepared adding $50 \mu \mathrm{L}$ GSSG standard, and $150 \mu \mathrm{L}$ of Assay Cocktail (MES buffer, cofactor mixture, enzyme mixture, water, and DTNB (5,5'-dithiobis-2-nitrobenzoic acid, Ellman's reagent). Total GSH was assessed spectrophotometrically at 405 or $414 \mathrm{~nm}$ with the end point method.

\section{Electron Microscopy Examination}

Tissue samples were fixed in $10 \%$ neutral buffered paraformaldehyde, washed in phosphate buffered saline ( $\mathrm{pH} 7.3)$, and post fixed in $2 \%$ aqueous osmium tetroxide for 2 hours. The samples were dehydrated through ascending grades of ethanol, infiltrated and embedded in Epon 812. Ultra thin sections were prepared using a Reichert Ultracut microtome. The sections were stained with aqueous solutions of uranyl acetate and lead citrate, and examined under Zeiss EM-9S-2 electtron microscope.

\section{Statistical Analysis}

Continuous variables were summarized using medians with interquartile ranges (IQRs). Differences among groups with respect to non-normally distributed parameters were tested using the Kruskal-Wallis test, whereas pairwise differences were compared by the Mann-Whitney test, at a Bonferroni-adjusted significance level. Analyses were conducted in SPSS 10 (SPSS, Inc., Chicago, IL). Data, in Figures, are expressed as median (line), interquartile range (box) and $95^{\text {th }}$ percentile range (whiskers). Extreme values are presented with circles. All reported p-values are two-tailed with a significance level of 0.05 .

\section{RESULTS}

All the animals completed the experiment without any adverse effects. Although we did not examine the small intestine histologically, we noticed that, at the end of the intes- tinal ischemia-reperfusion period (90 minutes), there was oedema and congestion of the intestinal wall.

\section{MDA Determination}

The values were significantly higher in Groups A and B compared to Groups C and D, $(\mathrm{p}<0.001)$, (Fig. 1). There were no significant differences between Groups A-B, and C$\mathrm{D}(\mathrm{p}=1)$.

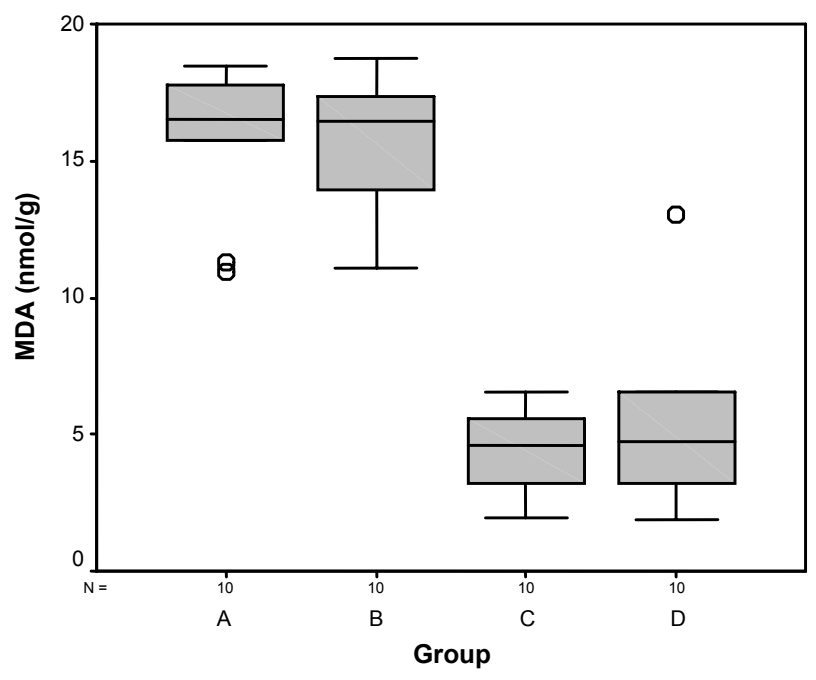

Fig. (1). Comparison of MDA.

\section{Total GSH Determination}

The values were significantly lower in Groups A and B, compared to Groups $\mathrm{C}$ and $\mathrm{D},(\mathrm{p}<0.05)$, (Fig. 2). There were no significant differences between Groups A-B, and C-D, $(\mathrm{p}=1)$.



Fig. (2). Comparison of GSH.

\section{MPO Determination}

There were no significant differences between the groups, although the values in Group A were higher than the other Groups, (Fig. 3).

The values of SGPT were higher in Group A compared to the other three Groups and the difference was significant only with Groups $\mathrm{C}$ and $\mathrm{D},(\mathrm{p}<0.05)$, (Fig. 4). There were no significant differences between Groups A-B, B-C, B-D, and C-D $(\mathrm{p}=1)$. 


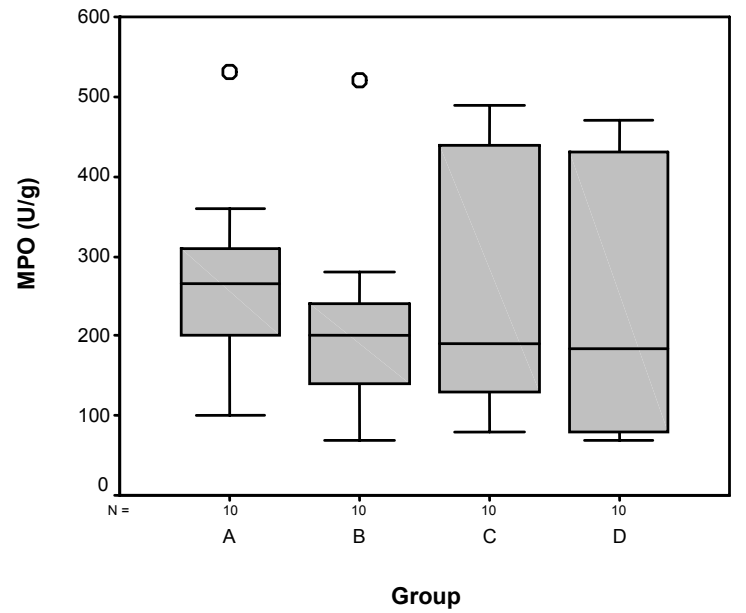

Fig. (3). Comparison of MPO.



Fig. (4). Comparison of SGPT.

The values of SGOT were not significantly different between the Groups.

\section{Electron Microscopy Examination}

In Group A, some hepatocytes were swollen and degenerated. Enlarged mitochondria with electrolucent matrix and disorganized cristae were observed (Fig. 5).

Smooth endoplasmic reticulum was dilated and glycogen granules accumulations were reduced (Fig. 5) or absent, leaving empty spaces within the cell matrix. Nuclei were slightly shrunk with nuclear membrane indentations and chromatin margination.

However, the most important changes were observed in the hepatic vessels. The endothelial cells of the sinusoids were vacuolated and often cell blebs protruded into the vessel lumen (Fig. 6). Rolls of red blood cells similar to a pile of coins were seen into the vessel lumen closely associating with endothelial cells. Cell debris and platelets filled the lumen of the portal veins. Disse space was frequently oedematous.

In Group B, hepatocytes were normal with round light nuclei (Fig. 7) and large nucleoli. Smooth endoplasmic reticulum had a normal appearance. Glycogen granules were abundant but mitochondria matrix was denser than normal
(Fig. 7). Lesions in endothelial cells were unremarkable. Liver cells and sinusoids, of Groups C and D, were normal.

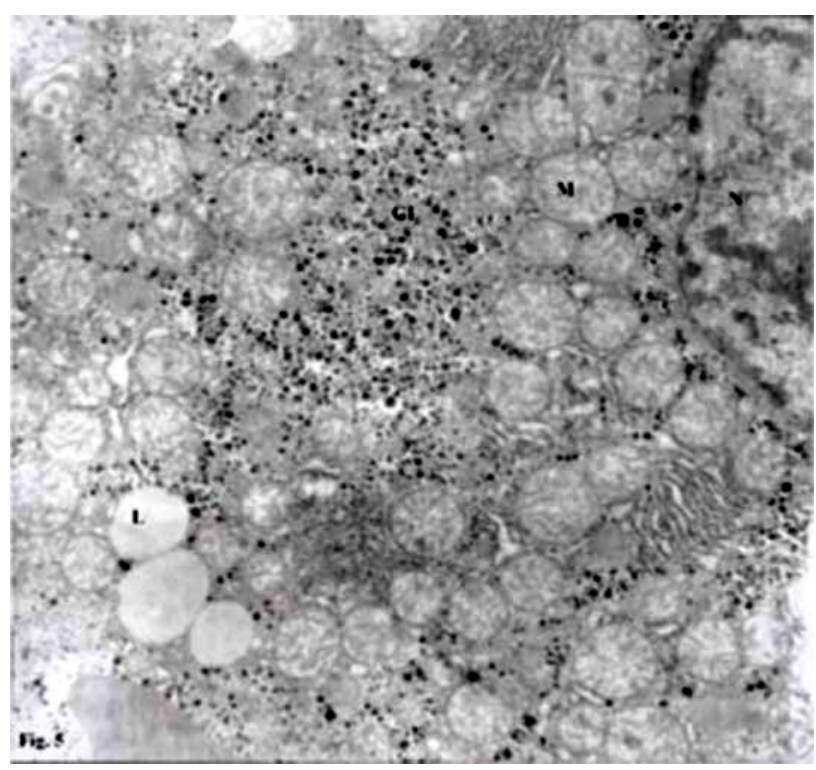

Fig. (5). Group A. mitochondria (M), glycogen granules (GL), nuclear (N), lipid droplets (L).

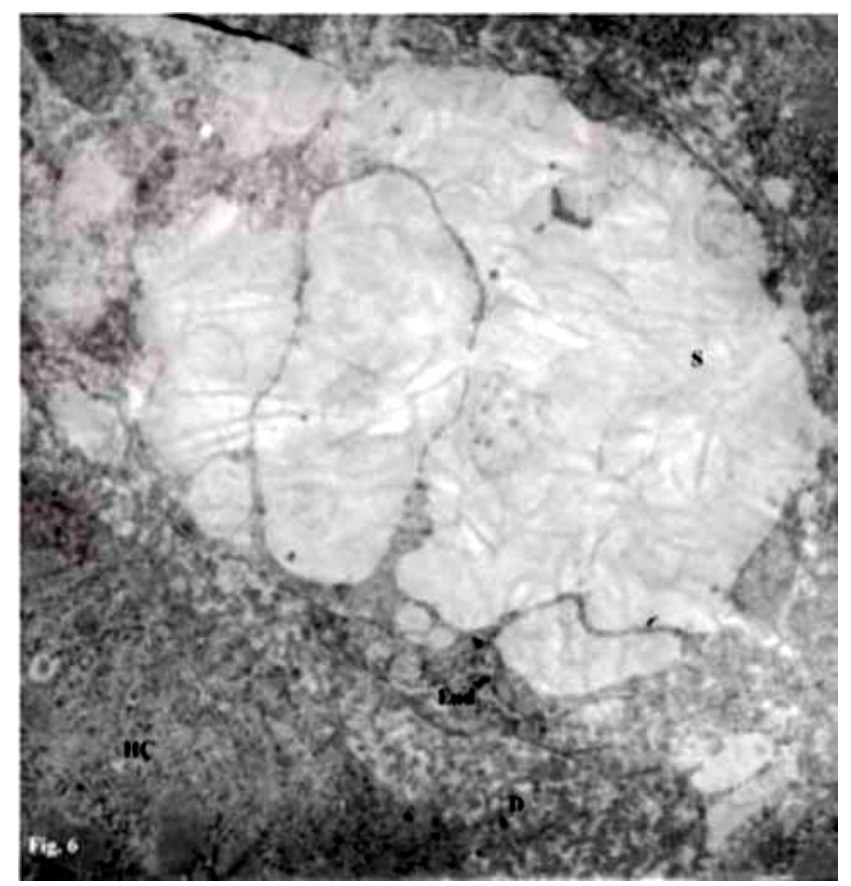

Fig. (6). Group A. Endothelial cell (End), sinusoid lumen (S), Disse space (D), hepatocyte (HC).

\section{DISCUSSION}

Intestinal ischemia-reperfusion injury is an experimental model that has been studied extensively for many years. The reason is that the small intestine is vulnerable to many pathologic situations like total parenteral nutrition, inflammatory diseases, chemotherapy, radiotherapy, and splachnic vasoconstriction in cases of shock $[10,11]$. In critically ill patients the small intestine has been invoked as the central and crucial organ of multiple organ failure syndrome $[12,13]$. 


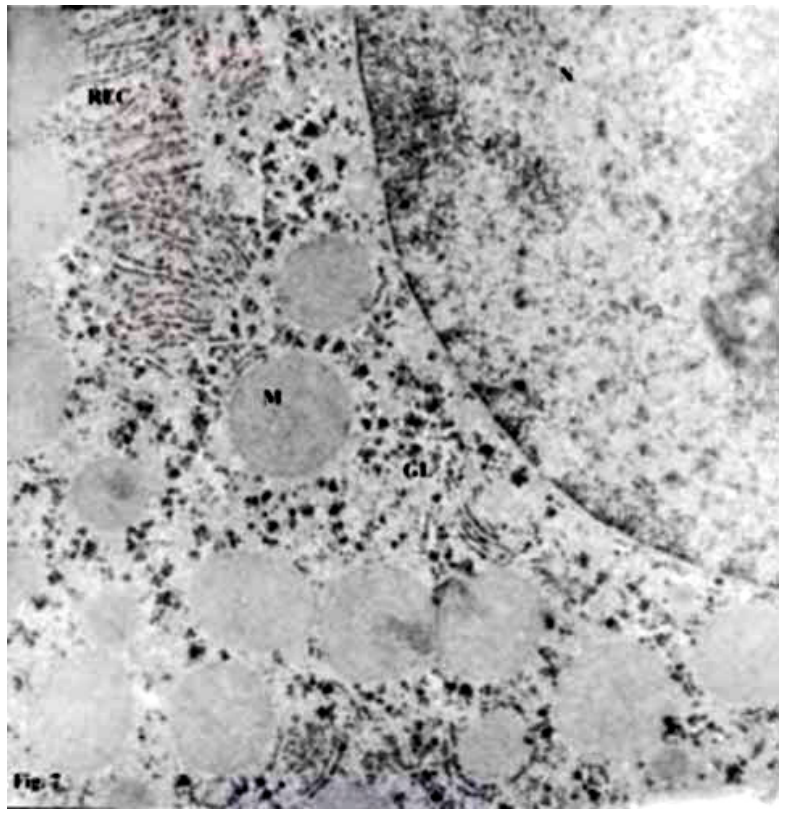

Fig. (7). Group B. nucleus (N), glycogen granules (GL), rough endoplasmic reticulum (REC), mitochondria (M)

The liver is affected by intestinal ischemia-reperfusion and its injury has been attributed to neutrophil accumulation, and oxygen free radicals production, leading to sinusoidal and venular endothelial cell damage with loss of hepatic vascular permeability barrier function $[14,15]$. Oxygen free radicals are either transferred from the small intestine or are produced in the liver from neutrophils, endothelial cells, parenchymal cells, and Kupffer cells [16]. Cytokines are also released from Kupffer cells, macrophages, and lymphocytes contributing to an increased inflammatory reaction [17].

In our study MDA was significantly higher in Groups A and $\mathrm{B}$ compared to Groups $\mathrm{C}$ and $\mathrm{D}(\mathrm{p}<0.001)$, showing that lipid peroxidation occurred in liver cells after intestinal ischemia-reperfusion. On the contrary we did not find significant differences in MPO, between the Groups. Although there is neutrophil accumulation in the sinusoids after 1 hour of reperfusion [7], longer reperfusion time is probably required to mediate their damage, as Poggetti et al. and Simpson et al. report, after 6 and 4 hours of reperfusion, respectively $[14,17]$. Liver cells injury was also indicated by the significant increase of SGPT in serum of Group A animals, compared to Groups C and D ( $<<0.05)$. Turnage et al. have found that SGPT was increased significantly during the ischemic period and there was a modest further increase during reperfusion [6].

In Group A, electron microscopy examination revealed significant liver cell injury with nucleus shrinkage and elimination of the mitochondria matrix. The same findings have been reported by other authors following intestinal or liver ischemia-reperfusion $[18,19]$. The presence of cytoplasmic blebs and cell debris in the vessel lumen as well as the Disse space oedema indicated severe endothelial damage. There was also increased accumulation of platelets and lymphocytes, probably due to the production of cytokines like Platelet Activating Factor (PAF). Pretreatment with the administration of the PAF antagonist (WEB2086) or T- lymphocyte depletion, attenuated the liver injury following intestinal ischemia-reperfusion injury $[20,21]$.
The antioxidant system of glutathione plays an important role for the protection of either intestinal mucous cells or hepatic cells from oxidative injury. There is a loss of reduced GSH in small intestine after ischemia-reperfusion [22], and also in liver a decrease in total GSH [23], but a rise in mitochondrial reduced GSH [24], after hepatic ischemiareperfusion. In our study, we found that total GSH was significantly lower in Group A compared to Groups C and D $(p<0.05)$, indicating that liver cells consumed GSH stores in order to compensate the production of oxygen radicals.

Glutamine has multiple functions. Except for participation in protein and nucleic acid production it plays an important role in acid-base balance as a precursor of urinary ammonia and also provides the source of glutamate to the glutathione system [25]. Experimental studies have proven the efficacy of glutamine given supplementary to total parenteral nutrition in attenuating the injury to the intestinal mucous cells and integrity of gut barrier function [26, 27]. Glutamine was given in an effort to attenuate the liver injury elicited by intestinal ischemia-reperfusion.

The biochemical markers did not prove liver protection by Alanyl-Glutamine dipeptide, as the values of MDA, and SGPT in Group B were not significantly different from Group A. Additionally MDA was significantly higher in Group B compared to Groups C and D $(\mathrm{p}<0.001)$. The administration of glutamine was not able to maintain the GSH stores in liver tissue, as there was no significant difference between Groups A and B, and total GSH was significantly lower in Groups $\mathrm{A}$ and $\mathrm{B}$, compared to Groups $\mathrm{C}$ and $\mathrm{D}$ $(\mathrm{p}<0.05)$. There was also no difference between Groups $\mathrm{C}$ and $\mathrm{D}$, indicating that 2 days of glutamine supplementation were not able to raise GSH stores in the liver. On the contrary electron microscopy examination of Group B showed significant differences concerning the appearance of the hepatocytes and endothelial cells, compared to Group A. Perhaps longer ischemia-reperfusion time is necessary for the biochemical markers to prove the liver protection.

Denno et al. have also found no increase of hepatic GSH in animals fed with glutamine for 4 days [28]. In the study of Hong et al. [8] the animals that were given glutamine for 5 days, maintained GSH stores and had lower values of liver enzymes in serum, after acetaminophen administration. Other authors have also found beneficial effect to the liver from glutamine dipetide supplementation for 7 and 5 days, mediated via glutathione synthesis $[9,29]$. In our study glutamine had a double protective role for both the gut and the liver, so probably longer glutamine supplementation would have resulted in higher liver GSH stores.

The supplementation of glutamine to total parenteral nutrition has been studied in ICU-patients who had fewer septic complications and better outcome after six months [30,31]. It has been also used in immunosuppressed patients undergoing bone marrow transplantation or having acute leukaemia, where it could hasten lymphocyte and neutrophil recovery $[32,33]$. Other authors did not find any advantages from the administration of glutamine in critically ill patients and newborns and infants $[34,35,36]$. Two recent reviews concluded that glutamine supplementation results in fewer septic complications and perhaps better outcome in ICU-patients receiving total parenteral nutrition $[37,38]$. 
In conclusion alanyl-glutamine dipeptide supplementation protected the hepatocytes from intestinal ischemiareperfusion injury. Further studies and longer administration time may confirm the beneficial results, from the use of glutamine, that have been reported in the literature.

\section{ACKNOWLEDGEMENTS}

We thank Mrs. Anna-Bettina Haidich, PhD Medical Statistics, for the statistical analysis.

\section{REFERENCES}

[1] Horton JW, Walker PB. Oxygen radicals, lipid peroxidation, and permeability changes after intestinal ischemia and reperfusion. J Appl Physiol 1993; 74: 1515-20.

[2] Grotz MR, Deitch EA, Ding J, Xu D, Huang Q, Regel G. Intestinal cytokine response after gut ischemia. Role of gut barrier failure. Ann Surg 1999; 229: 478-86.

[3] Granger DN. Role of xanthine oxidase and granulocytes in ischemia reperfusion injury. Am J Physiol 1988; 255: H1269-75.

[4] Moore EE, Moore FA, Francoise RJ, Kim FJ, Biffl WL, Banerjee A. The postischemic gut serves as a priming bed for circulating neutrophils that provoke multiple organ failure. J Trauma 1994; 37: 881-7.

[5] Yao Y, Yu Y, Wu Y, Shi Z, Sheng Z. The role of gut as a cytokinegenerating organ in remote organ dysfunction after intestinal ischemia and reperfusion. Clin Med J (Engl) 1998; 111: 514-8.

[6] Turnage RH, Kadesky KM, Myers SI, Guice KS, Oldham KT. Hepatic hypoperfusion after intestinal reperfusion. Surgery 1996; 119: 151-60.

[7] Horie Y, Wolf R, Miyasaka M, Anderson DC, Granger DN. Leukocyte adhesion and hepatic microvascular responses to intestinal ischemia/reperfusion in rats. Gastroenterology 1996; 111: 666-73.

[8] Hong RW, Rounds JD, Helton WS, Robinson MK, Wilmore DW. Glutamine preserves liver glutathione after lethal hepatic injury. Ann Surg 1992; 215: 114-9.

[9] Yu JC, Jiang ZM, Li DM. Glutamine: a precursor of glutathione and its effect on liver. World J Gastroenterol 1999; 5: 143-146.

[10] van der Hulst RR, von Meyenfeldt MF, van Kreel BK, et al. Gut permeability, intestinal morphology, and nutritional depletion. Nutrition 1998; 14: 1-6.

[11] Fiddian-Green RG. Splanchnic ischaemia and multiple organ failure in the critically ill. Ann R Coll Surg Engl 1988; 70: 128-134.

[12] Wilmore DW, Smith RJ, O'Dwyer ST, Jacobs DO, Ziegler TR, Wang XD. The gut: a central organ after surgical stress. Surgery 1988; 104: 917-923.

[13] Carrico Cl, Meakins JL, Marshall JC, Fry D, Maier RV. Multipleorgan-failure syndrome. Arch Surg 1986; 121: 196-208.

[14] Poggetti RS, Moore FA, Moore EE, Bensard DD, Anderson BO, Banerjee A. Liver injury is a reversible neutrophil-mediated event following gut ischemia. Arch Surg 1992; 127: 175-9 .

[15] Poggetti RS, Moore FA, Moore EE, Koeike K, Banerjee A. Simultaneous liver and lung injury following gut ischemia is mediated by xanthine oxidase. J Trauma 1992; 32: 723-8.

[16] Turnage RH, Bagnasco J, Berger J, Guice KS, Oldham KT, Hinshaw DB. Hepatocellular oxidant stress following intestinal ischemia-reperfusion injury. J Surg Res 1991; 51: 467-71.

[17] Simpson R, Alon R, Kobzik L, Valeri CR, Shepro D, Hechtman HB. Neutrophil and nonneutrophil-mediated injury in intestinal ischemia-reperfusion. Ann Surg 1993; 218: 444-54.

[18] Giakoustidis AE, Giakoustidis DE, Iliadis S, et al. Attenuation of intestinal ischemia-reperfusion induced liver and lung injury by in- traperitoneal administration of (-)-epigallocatechin-3-gallate. Free Radic Res 2006; 40: 103-10.

[19] Matsumoto F, Sakai H, Yamaguchi M, et al. Allopurinol reduced hepatic ischemia-reperfusion injury exacerbated by inhalation of high-concentration oxygen in rats. Eur Surg Res 1997; 29: 429-37.

[20] Horie Y, Wolf R, Russell J, Shanley TP, Granger DN. Role of Kupffer cells in gut ischemia-reperfusion-induced hepatic microvascular dysfunction in mice. Hepatology 1997; 26: 1499-505.

[21] Horie Y, Wolf R, Chervenak RP, Jennings SR, Granger DN. Tlymphocytes contribute to hepatic leukostasis and hypoxic stress induced by gut ischemia-reperfusion. Microcirculation 1999; 6: 267-80.

[22] Grisham MB, Hernandez LA, Granger DN. Xanthine oxidase and neutrophil infiltration in intestinal ischemia. Am J Physiol 1986; 251: G567-74.

[23] Stein HJ, Oosthuizen MM, Hinder RA, Lamprechts H. Oxygen free radicals and glutathione in hepatic ischemia/reperfusion injury. $\mathrm{J}$ Surg Res 1991; 50: 398-402.

[24] Kurokawa T, Kobayashi H, Nonami T, Harada A, Nakao A, Takagi $\mathrm{H}$. Mitochondrial glutathione redox and energy producing function during liver ischemia and reperfusion. J Surg Res 1996; 66: 1-5.

[25] Lacey JM, Wilmore DW. Is glutamine a conditionally essential amino acid ? Nutr Rev 1990; 48: 297-309.

[26] Wu GH, Wang H, Zhang YW, Wu ZH, Wu ZG. Glutamine supplemented parenteral nutrition prevents intestinal ischemiareperfusion injury in rats. World J Gastroenterol. 2004; 10: 2592-4.

[27] Tazuke Y, Wasa M, Shimizu Y, Wang HS, Okada A. Alanylglutamine-supplemented parenteral nutrition prevents intestinal ischemia-reperfusion injury in rats. JPEN 2003; 27: 110-5.

[28] Denno R, Rounds JD, Faris R, Holejko LB, Wilmore DW. Glutamine-enriched total parenteral nutrition enhances plasma glutathione in the resting state. J Surg Res 1996; 15: 35-8.

[29] Matilla B, Ortiz J, Gonzalez P, et al. Effects of parenteral nutrition supplemented with glutamine or glutamine dipeptides on liver antioxidant and detoxication systems in rats. Nutrition 2000; 16: 125-8.

[30] Griffiths RD, Jones C, Palmer TE. Six-month outcome of critically ill patients given glutamine-supplemented parenteral nutrition. Nutrition 1997; 13: 295-302.

[31] Goeters C, Wenn A, Mertes N, et al. Parenteral L-alanyl-Lglutamine improves 6-month outcome in critically ill patients. Crit Care Med 2002; 30: 2032-7.

[32] Ziegler TR, Bye RL, Persinger RL, Young LS, Antin JH, Wilmore DW. Effects of glutamine supplementation on circulating lymphocytes after bone marrow transplantation: a pilot study. Am J Med Sci 1998; 315: 4-10.

[33] Scheid C, Hermann K, Kremer G, et al. Randomized, double-blind, controlled study of glycyl-glutamine-dipeptide in the parenteral nutrition of patients with acute leukemia undergoing intensive chemotherapy. Nutrition 2004; 20: 249-54.

[34] Palmer TE, Griffiths RD, Jones C. Effect of parenteral L-glutamine on muscle in the very severely ill. Nutrition 1996; 12: 316-320.

[35] Albers MJ, Steyerberg EW, Hazebroek FW, et al. Glutamine supplementation of parenteral nutrition does not improve intestinal permeability, nitrogen balance, or outcome in newborns and infants undergoing digestive-tract surgery: results from a double-blind, randomized, controlled trial. Ann Surg. 2005; 241: 599-606.

[36] Hulsewe KW, van Acker BA, Hameeteman W, et al. Does glutamine-enriched parenteral nutrition really affect intestinal morphology and gut permeability? Clin Nutr. 2004; 23: 1217-25.

[37] Novak F, Heyland DK, Avenell A, Drover JW, Su X. Glutamine supplementation in serious illness: a systematic review of the evidence. Crit Care Med. 2002; 30: 2022-9.

[38] De-Souza DA, Greene LJ. Intestinal permeability and systemic infections in critically ill patients: effect of glutamine. Crit Care Med 2005; 33: 1125-35. 